\title{
Evaluation of nitrogen supply on arsenic stress responses of rice (Oryza sativa L.) seedlings
}

\author{
S. Srivastava \\ Institute of Environment and Sustainable Development, Banaras Hindu University, Varanasi, India
}

\begin{abstract}
In the present study, the effects of nitrate supply (low nitrogen: LN and high nitrogen: HN) on arsenate $[\mathrm{As}(\mathrm{V})]$ stress $(25 \mathrm{M})$ responses in rice seedlings were monitored for $7 \mathrm{~d}$. The $\mathrm{LN}+\mathrm{As}$ treatment resulted in significant decline in As concentration $\left(848 \mathrm{~g} \mathrm{~g}^{-1} \mathrm{DW}\right)$ than that in As alone treatment $\left(1434 \mathrm{~g} \mathrm{~g}^{-1}\right.$ DW) in roots but no significant effect was seen in shoot. In contrast, $\mathrm{HN}+$ As treatment showed significant increase in shoot As $\left(6.86 \mathrm{~g} \mathrm{~g}^{-1} \mathrm{DW}\right)$ as compared to As alone treatment $\left(3.43 \mathrm{~g} \mathrm{~g}^{-1} \mathrm{DW}\right)$. The level of nitrate was increased in roots but declined in shoots in As alone treatment. Surprisingly, no improvement in nitrate level was seen in $\mathrm{HN}+$ As as compared to that in As treatment in both root and shoot. The expression analysis of transporters of As (Pht1;1, Lsi2 and NIP1;1) and nitrate (NRT2;1, NRT2;3a, NRT2;4) showed significant differences in expression patterns in $\mathrm{As}, \mathrm{LN}+\mathrm{As}$ and $\mathrm{HN}+\mathrm{As}$ treatments.
\end{abstract}

\section{INTRODUCTION}

Arsenic (As) is a nonessential carcinogenic metalloid whose entry into grains of rice plants has raised health concerns for millions of people dependent on rice as staple food. Further, several studies have been conducted till date to see the effects of elements like silica (Si), phosphate, selenium (Se) and sulfur (S) on As stress responses and As concentrations in rice. Nitrogen $(\mathrm{N})$ is a macronutrient required for the biosynthesis of nucleic acids, proteins, chlorophyll, and phytohormones and its availability regulates plant growth. The conventional methods of crop cultivation rely on the application of $\mathrm{N}$ fertilizers in high amounts to obtain high yields from high yielding short duration varieties. The impact of nitrogen $(\mathrm{N})$ supply on rice plants has not been studied with respect to As stress. It was considered worthwhile since $\mathrm{N}$ not only may impact As responses in rice but also can have positive impact in terms of reducing $\mathrm{N}$ fertilizer cost. Hence, the present experiments were, hence, planned to evaluate the impact of variable $\mathrm{N}$ supply on rice plants subjected to $\mathrm{As}(\mathrm{V})$ stress for 3 and $7 \mathrm{~d}$.

\section{METHODS}

\subsection{Plant material, growth and treatments}

The study was conducted on Oryza sativa var. IR64. The 4-d old seedlings were placed in $500 \mathrm{~mL}$ beaker having $300 \mathrm{~mL}$ of $1 / 2$ Kimura solution $(\mathrm{pH} 5.5$, with $0.457 \mathrm{mMN}$ ). At 9 th d, seedlings were divided into three sets. One set continued to grow in $1 / 2$ Kimura medium with $0.457 \mathrm{mMN}$ (control set). Of the other two sets, one set received $0.0457 \mathrm{mMN}$ $($ Low $\mathrm{N})$ and other received $0.914 \mathrm{mM} \mathrm{S}($ High N). The
Kimura medium contained three sources of $\mathrm{N}: \mathrm{KNO}_{3}$, $\mathrm{Ca}\left(\mathrm{NO}_{3}\right)_{2}$ and $\left(\mathrm{NH}_{4}\right)_{2} \mathrm{SO}_{4}$. For Low $\mathrm{N}$ treatment, the amount of each source was reduced in equal proportion and salts were replaced with $\mathrm{KCl}, \mathrm{CaCl}_{2}$ and $\mathrm{MgSO}_{4}$ in order to avoid deficiency of $\mathrm{K}, \mathrm{Ca}$ and $\mathrm{S}$. For High $\mathrm{N}$ treatment, an additional $0.457 \mathrm{mM}$ of $\left(\mathrm{NH}_{4}\right)_{2} \mathrm{NO}_{3}$ was added. Then on 16 th $\mathrm{d}$, each of the three set was divided into two separate sets constituting: one control for each condition and one subjected to $25 \mu \mathrm{M}$ arsenate $[\mathrm{As}(\mathrm{V})]$. The harvesting was done at $3 \mathrm{~d}$ and $7 \mathrm{~d}$.

\subsection{Biochemical, molecular and arsenic analysis}

The root and shoot were then separated and oven-dried at $80-85^{\circ} \mathrm{C}$ till constant dry weight. The acid digested sample was analyzed with ICP-MS. Cysteine level was measured following the protocol of Gaitonde (1967). The activities of superoxide dismutase and guaiacol peroxidase were assayed as described in Srivastava et al. (2006). For proline estimation, the method of Bates et al. (1973) was followed. The level of nitrate was estimated following the protocols of Kamphake et al. (1967). All the primers used for real-time PCR were from exon-intron boundary and designed using web-based Quant-prime tool. The protocols for RNA extraction, cDNA synthesis, real-time PCR analyses and $\log 2$ fold-calculation were same as described in our earlier work (Srivastava et al., 2014).

\section{RESULTS AND DISCUSSION}

\subsection{Arsenic concentrations}

Arsenic was found to be predominantly concentrated in roots than in shoots. The concentrations of As $\left(\mu \mathrm{g} \mathrm{g}^{-1}\right.$ 

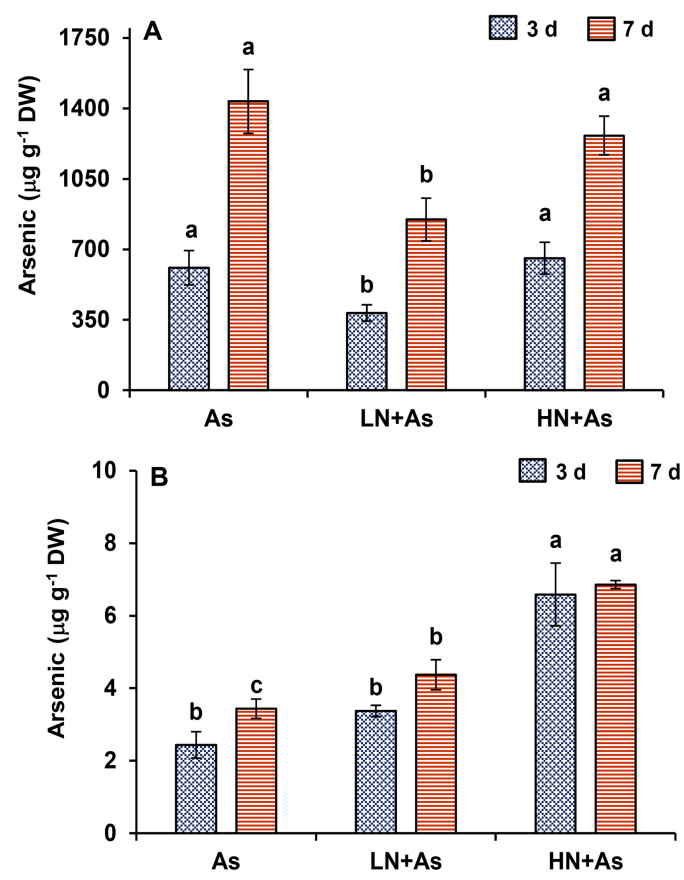

Figure 1. Accumulation of arsenic by rice roost (A) and shoot (B) exposed to arsenate for 3 and $7 \mathrm{~d}$. All values are means of triplicates \pm S.D. ANOVA significant at $p \leq 0.01$. Different letters indicate significantly different values at a particular duration (DMRT, $\mathrm{p} \leq 0.05$ ).

DW) were 608 and 1434 in roots and 2.44 and 3.45 in shoot at $3 \mathrm{~d}$ and $7 \mathrm{~d}$, respectively. In shoot, As concentrations increased further 3.3 and 4.4 in $\mathrm{LN}+\mathrm{As}$ and to 6.6 and $6.9 \mathrm{in} \mathrm{HN}+\mathrm{As}$ at $3 \mathrm{~d}$ and $7 \mathrm{~d}$, respectively. In roots, $\mathrm{LN}+$ As treatment lead to reduction in As concentrations to $383(37 \%)$ and $848(41 \%) \mu \mathrm{gg}^{-1} \mathrm{DW}$ as compared to As alone treatment. However, $\mathrm{HN}+\mathrm{As}$ treatment caused further increase in As concentrations to $655(8 \%)$ at $3 \mathrm{~d}$ but induced a decline to $1264(11 \%)$ at $7 \mathrm{~d}$ (Fig. 1).

\subsection{Biochemical parameters}

The level of cysteine showed a significant increase in response to As stress and $\mathrm{N}$ treatments. However, $\mathrm{HN}$ and $\mathrm{HN}+\mathrm{As}$ treatment induced higher increases in root cysteine as compared to $\mathrm{LN}$ and $\mathrm{LN}+\mathrm{As}$ treatment that caused greater increases in shoot cysteine levels (Fig. 2). There were changes in activities of various antioxidant enzymes like superoxide dismutase and guaiacol peroxidase. Nitrate, proline and photosynthetic pigment level were also altered. The expression analysis of important transporters of nitrate and As was performed at $3 \mathrm{~d}$ and $7 \mathrm{~d}$ in both roots

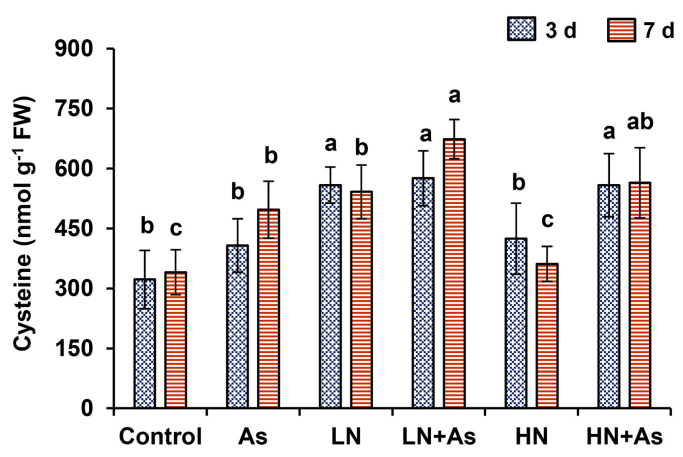

Figure 2. Effect of As and $\mathrm{N}$ treatments on cysteine level in shoot of rice. All values are means of triplicates \pm S.D. ANOVA significant at $p \leq 0.01$. Different letters indicate significantly different values at a particular duration (DMRT, $\mathrm{p} \leq 0.05)$.

and shoot. Variable expression patterns in different treatments were observed for Pht1;1, Lsi2, NIP1;1, NRT2;1, NRT2.3a, and NRT2.4.

\section{CONCLUSIONS}

In conclusion, nitrate supply has profound influence on responses and As concentration of rice plants exposed to As. The strategy needs to be analyzed further at field scale in future.

\section{ACKNOWLEDGEMENTS}

Authors gratefully acknowledge the support from funding received from UGC Startup Grant (F.30112/2015(BSR).

\section{REFERENCES}

Bates, L.S. 1973. Rapid determination of free proline for water-stress studies. Plant Soil 39(1): 205-207.

Gaitonde, M. K. 1967. A spectrophotometric method for the direct determination of cysteine in the presence of other naturally occurring amino acids. Biochem. J. 104(2): 627-633.

Kamphake, L.T., Hannah, S.A. \& Cohen, T.M. 1967. Automated analysis for nitrate by hydrazine reduction. Water Res. 1(3): 2015-216.

Srivastava, A.K., Srivastava, S., Mishra, S. \& D'Souza, S.F. 2014. Identification of redox-regulated components of arsenate $(\mathrm{As}(\mathrm{V}))$ tolerance through thiourea supplementation in rice. Metallomicms 6(9): 1718-1730.

Srivastava, S., Mishra, S., Tripathi, R.D., Dwivedi, S. \& Gupta, D.K. 2006. Copper-induced oxidative stress and responses of antioxidants and phytochelatins in Hydrilla verticillata (L.f.) Royle. Aquat. Toxicol. 80(4): 405-415. 